\title{
Fair trade: what does it mean and why does it matter?
}

\begin{abstract}
The paper begins by locating the issue of trade within the broader literature on international and global justice. It then sets out eight different conceptions of 'fair trade', and examines the principles that lie behind them. They fall into three broad categories: procedural fairness accounts, which apply principles of equal treatment to the international rules under which trade takes place; producers' entitlement accounts, which claim that trade must be structured so that all participants are safeguarded against harms such as exploitation or poverty; and fair exchange accounts, which require trade to be conducted on terms that produce a particular division of resources or benefits between the trading partners. These conceptions are partly complementary, but may on occasion pull in different directions, requiring us to reflect on the relative weights we attach to different aspects of fairness in trade.
\end{abstract}

Keywords: equal division, fair trade, global justice, human rights, reciprocity.

In the debate over 'justice beyond the state', a consensus is emerging that the sharp distinction rehearsed in many textbooks between 'cosmopolitans' and 'statists' (or 'nationalists') needs to be superseded. Increasingly, philosophers locate themselves somewhere on the middle ground. They acknowledge that there is a distinctive form of distributive justice - social justice - that applies only within states, but there are other forms that apply internationally or globally, and that may constrain the pursuit of social justice domestically. ${ }^{1}$ Attention has focussed particularly on international practices that impose costs or create benefits that need to be allocated somehow between the citizens of different countries. Trade features prominently here because of its evident impact, for better or worse, on the lives of so many people worldwide.

\footnotetext{
${ }^{1}$ Examples include Kok-Chor Tan, Justice Beyond Borders: Cosmopolitanism, Nationalism, and Patriotism (Cambridge: Cambridge University Press, 2004), Gillian Brock, Global Justice: A Cosmopolitan Account (Oxford: Oxford University Press, 2009) and (reference removed). For an excellent critical overview, see Patti Lenard and Margaret Moore, 'A Defence of Moderate Cosmopolitanism and/or Moderate Liberal Nationalism’ in Will Kymlicka and Kathryn Walker (eds.), Rooted Cosmopolitanism: Canada and the World (Vancouver: UBC Press, 2012), pp. 47-68.
} 
But how should we think about fairness in trade? Should we view it through the lens of international justice - justice between states - or through the lens of global justice justice between people worldwide? Even at first glance, one can see that neither an exclusively international justice approach nor an exclusively global justice approach is going to be adequate. On the one hand, trade is something that takes place between states, according to rules negotiated between states, which suggests that we should treat it as part of international justice, or 'The Law of Peoples' in Rawls' sense - i.e. the general terms on which independent states should co-operate with one another to their mutual advantage. ${ }^{2}$ On the other hand, it seems to form part of global justice proper, since the economic consequences of trade bear directly on the life-chances of individuals, in particular determining whether they are able to rise above conventionally-defined global poverty lines.

An examination of public policy related discussions of fair trade reveals further complexity. On the one hand, organizations such as the Fair Trade movement seem primarily concerned with development issues - how to change the rules of trade so they work to help poor people in developing countries. On the other hand, both unions and businesses in developed countries complain of unfair competition from goods made in developing countries whose costs are lower - sometimes because of violation of standards that are enforced in developed countries, such as environmental and labour laws.

So 'fair trade' is being invoked both by people who want to change the rules of international trade so that they are more favourable to badly-off workers in developing countries, and by those who want to give greater protection to established industries in rich countries. It seems unlikely that this involves no more than an empirical dispute about the application of a shared idea of fair trade. It seems rather that there may be significant disagreement about what makes trade fair: what conditions a given trading practice has to meet in order for us to say that it's a fair practice. In particular, there is controversy about the relationship between fair trade and free trade: is fair trade simply really free trade, trade in the absence of the many and varied barriers to exchange that

\footnotetext{
${ }^{2}$ See John Rawls, The Law of Peoples (Cambridge, MA: Harvard University Press,
} 1999). 
currently exist in the global economy, or does fair trade require that exchanges be regulated - whether by governments or by international bodies - in such a way as to prevent specific outcomes that a global free market might otherwise produce? My interest is in these conceptual questions, which may, however, also turn out to have normative dimensions. We should not assume from the start that we will be able to discover a single, definitive concept of fair trade. There may instead be several conceptions, each used for a different purpose and with a different normative basis. It wouldn't however follow, as some have claimed, that fair trade is merely a subjective idea, used to endorse whichever bundle of trade policies the speaker happens to favour. ${ }^{3}$ It would mean, though, that different aspects of fairness, a broad idea itself, were being emphasized in different practical contexts in which fair trade was being discussed.

So how should we think about it? There are a couple of early forks in the road to negotiate. One has to do with identifying the relevant participants in trading relationships: are they individual people, or corporations, or states? ${ }^{4}$ Descriptively, all of these are involved, but from a normative perspective which relationships are fundamental? Are we to think about the general way in which state A organizes its trade with state $\mathrm{B}$ - for example the rules it applies to goods imported from state B, in terms of quotas, tariffs, etc.? Or are we to think about the relationship between an individual person in state A - a coffee grower, say - and the multinational corporation that buys his product, or indeed the person in state B who finally consumes it? Debates about fair trade seem to occur at both levels. People are concerned that only a tiny fraction of the coffee's selling price in B goes to the grower in A, and regard that as unfair. But there is also concern about the way in which powerful states impose unfair

\footnotetext{
${ }^{3}$ See, for example, a comment from the head of India's delegation to the GATT talks in the 1990s: 'Fairness is dictated by one's own economic interests. One decides on whether something is fair or not based on one's goal in the negotiations.' (cited in Celia Albin, Justice and Fairness in International Negotiation (Cambridge: Cambridge University Press, 2001), p. 135.)

${ }^{4}$ C.f. here the three 'ontologies of trade identified by Risse and Wollner in Matthias Risse and Gabriel Wollner, 'Three Images of Trade: on the place of trade in a theory of global justice', Moral Philosophy and Politics 1 (2014), pp. 201-25. See also James' distinction between 'individualist and 'internationalist' conceptions of the trade regime in Aaron James, Fairness in Practice: a Social Contract for a Global Economy (Oxford: Oxford University Press, 2012).
} 
trading rules on weaker states, which although it may have ramifications at the individual level does not seem reducible to unfairness between individuals (think, for example, of the Soviet-dominated trading system under Comecon). Standing back from these debates, one can think of reasons to justify either approach. Since our deepest concern in thinking about trade from a normative perspective is likely to be the effects it has on individual lives, this suggests understanding fairness in terms of the benefits and burdens that trade creates for individual people. On the other hand, since trade is also a rule-governed practice that operates on a large scale, we have good reason to direct our attention to the agents who make the rules, and can therefore change the form that the practice takes, which means states and international bodies such as the WTO.

For present purposes I want to leave it open which branch to follow here - i.e. whether it is more illuminating to think about fair trade as a relationship between states or between individual persons within those states. I will discuss conceptions of fair trade that are state-focussed and others that are person-focussed. The second fork we need to negotiate is more philosophical: how far should we understand fairness in trade as internal to the practice of trade itself, and how far should we subsume it under a wider conception of global justice? ${ }^{5}$ That is, should we look at the terms on which the transactions that constitute trade in a particular commodity, say, are conducted, and ask whether those terms are fair as between the parties involved in that branch of trade? Or should we look more widely at the consequences of the trade that is carried out under those terms, asking for example about whether it is consistent with some global principle of distributive justice such as the Rawlsian difference principle. Does it help to raise the position of the weaker trading partner above some poverty line, or indeed raise that party's position to the maximum extent possible? The question, in other words, is whether we should be looking directly at trade itself, as a practice within which commodities are exchanged between different countries, or individuals or firms in those countries, at certain prices and according to certain ground rules, and asking whether the practice is fair, by some criterion; or whether we should be considering the

\footnotetext{
${ }^{5}$ C.f. Caney's distinction between 'isolationist' and 'integrationist' approaches to the climate change problem in Simon Caney, 'Just Emissions', Philosophy and Public Affairs 40 (2012), p. 259. The contrast between external and internal demands of justice applied to trade is explored more fully in Florian Ostmann, 'Moral Constraints on Prices in International Commercial Transactions', this issue.
} 
impact that trade may have on the overall position of the trading partners, for example whether it renders them more or less equal in resources than they were before the exchange. It would be naïve to think that these two issues are really one and the same. There are of course conceptions of justice and fairness that are entirely procedural and that would therefore make the second question redundant; there are also ethical theories such as simple utilitarianism that attach no moral weight to procedural issues and look only at the overall consequences of different practices. But these are both extreme positions. For most people, I suspect, who believe in the value of fair trade, it matters both in its own right - it is important that when parties exchange goods they should do it on terms that are fair, in particular terms that do not exploit either side - and for the consequences that it brings: fair trade is also trade that leaves both parties reasonable well off by some standard. That is certainly the assumption of those who see fair trade as making a significant contribution to the relief of global poverty.

I believe that this two-sided approach to the value of fair trade is essentially correct. Even if we first come to it through thinking about solutions to global poverty, we should recognize that fair trade is an independent principle of international justice, one that should also govern relations between countries standing well above the poverty threshold. The question that arises, however, is whether these two concerns always point in the same direction or whether fair trade does not turn out to display the features of an 'essentially contested concept' ${ }^{6}$ In order to answer this question, I will examine the various explicit or implicit definitions of fairness in trade to be found in academic and political discussion, and suggest that these fall into three main groups. The upshot is the concept of fair trade is multidimensional, and although in some cases improvements along one dimension will also bring improvements along the others, this will not always be so - in which case we may have to decide which aspect of fairness matters to us most.

One last introductory point: without offering a formal definition of trade, I shall understand it as a practice that involves the voluntary exchange of commodities or services for mutual advantage. ${ }^{7}$ That means, self-evidently, that both trading partners

\footnotetext{
${ }^{6}$ An idea first introduced by W.B. Gallie in 'Essentially Contested Concepts', Proceedings of the Aristotelian Society 56 (1955-6), pp. 167-98.
} 
expect to be better off as a result of their exchange. So we should not count as trade an exchange in which one party buys a product as an act of charity, the product being worth less to the buyer than the price she has paid. On the other hand buying, say, Fair Trade coffee at a higher price than regular coffee with the intention that the coffee grower should have a decent standard of life will count as engaging in trade so long as the coffee is still worth more to the consumer than the cost of buying it. ${ }^{8}$ Trading, in other words, does not entail attempting to maximise the benefit received from exchange; it does entail only exchanging where there is mutual advantage. This, then, set some limits to what can count as a conception of fair trade. It rules out any proposed definition of 'fair trade' that implies that one party has an obligation to engage in exchanges that are not in fact beneficial to them.

After these preliminaries, it is time to begin examining different ways in which the concept of fair trade has been used, looking in each case to see what the underlying normative principle or principles are. These are drawn from the existing literature on trade, although the concept of 'fair trade' is rarely defined explicitly in the sources I have consulted. ${ }^{9}$ What we find instead is that existing trade practices are condemned for being unfair or exploitative, and then various proposals are made for reforming these practices, from which one can try to infer the understanding of fairness that lies behind the criticism and the ensuing proposal. Since I am trying to capture these various

\footnotetext{
7 'Voluntary' is used here in the sense of 'uncoerced'. Trade does not cease to be trade because one party is placed in circumstances such that they have little option but to agree to an exchange that is advantageous to them, but much less so than they would have obtained under better background conditions. Such exchanges are likely to constitute unfair trade according to one of the criteria discussed below. I do not consider here the separate issue of whether states are always voluntary participants in the international trading regime.

${ }^{8}$ Here I use an individual-to-individual example to make the point, but the same applies if, as suggested above, we also think of trade as something that occurs at macro-level between states.

${ }^{9}$ In this respect, my approach differs from that adopted in Steven Suranovic, 'A Positive Analysis of Fairness with Applications to International Trade', The World Economy 23 (2000), pp. 283-307. Suranovic begins by looking at possible general meanings of 'fairness' and then asking what these would mean when applied to the case of trade.
} 
intuitive senses of 'fairness', the vocabulary I use does not always follow conventional usage in trade negotiations and elsewhere.

1. Two parties trade fairly when the terms of exchange are the same for both. I shall refer to this conception of fair trade as 'reciprocity', although in the literature this term is often used to describe something else, namely that in trade negotiations each party matches the concessions offered by the other. ${ }^{10}$ This understanding of fair trade views it as primarily a relationship between states. Trade is seen as a practice governed by certain rules, and fairness means that the same rules are applied by each trading partner to the imports and exports of the other. So, for example, if state $\mathrm{A}$ is trading with state B and B imposes a tariff on goods imported from A, A must not impose a higher tariff on goods imported from B; if B imposes no tariff at all, neither must A. The underlying idea here seems to be that each party should be given an equal opportunity to benefit from the advantages that trade offers. ${ }^{11}$ This applies both to whole countries and to individual producers within them - so for example a manufacturer in B should have the same chance to sell goods to consumers in A as a manufacturer in A has to sell to consumers in $\mathrm{B}$, at least as far as the rules governing trade are concerned. ${ }^{12}$

2. A distinct, though related, conception of fair trade is non-discrimination, which requires states to extend the same conditions of trade to all of their trading partners. This principle appears prominently in trade negotiations such as GATT. ${ }^{13}$ It was used

\footnotetext{
${ }^{10}$ For a discussion of reciprocity in this second sense, see Andrew Brown and Robert Stern, 'Concepts of Fairness in the Global Trading System', Pacific Economic Review 12 (2007), pp. 293-318.

${ }^{11}$ Indeed this understanding of trade is sometimes referred to as the equal access conception of reciprocity. See Kenneth Abbott, 'Defensive Unfairness: The Normative Structure of Section 301,' in Jagdish Bhagwati and Robert Hudec (eds.), Fair Trade and Harmonization: Prerequisites for Free Trade. Vol. 2: Legal Analysis (Cambridge, MA: MIT Press, 1996), p. 428.

${ }^{12}$ For an extended discussion and critique of reciprocity-based conceptions of fair trade see James Christensen, 'Fair Trade, Formal Equality, and Preferential Treatment', Social Theory and Practice 41 (2015), pp. 505-26, at pp. 515-19.
} 
in these negotiations primarily to encourage states to lower their tariff barriers, i.e. to extend their most favourable current trade rules to all trading partners, but it can also be seen as an attempt to create fairness in the form of a 'level playing field', whereby everyone attempting to export goods to country A has the same opportunity to do so. It need not entail reciprocity, since A can practice non-discrimination towards $\mathrm{B}, \mathrm{C}$, and $\mathrm{D}$ without insisting that these countries reciprocate the terms that it is offering. Nonetheless the two principles naturally combine if one thinks of the trading system as a whole and wants all parties to exchange goods and services under a uniform set of rules (or to put it more colloquially, if one wants the playing field to be level in all directions).

3. One limitation of simple reciprocity plus non-discrimination is that it takes no account of the relative strength or weakness of the potential trading partners, for example the scale and level of development of their industrial base. Formally the rules governing trade may be the same for all, but some parties may already be at a considerable advantage by virtue of vastly superior technology, for instance. So to counteract this unfairness, a more complex version of reciprocity may be proposed. ${ }^{14}$ This allows countries to apply different sets of rules to their various trading partners so long as they can justify the variation on publicly-approved grounds ('special and differential treatment' is the phrase commonly used to describe this ${ }^{15}$ ). An obvious example would be the provision in the GATT of rules that allowed developing countries

\footnotetext{
${ }^{13}$ For an analysis of the principles of fairness that were routinely invoked in the Uruguay round of GATT negotiations, in particular, see Albin, Justice and Fairness in International Negotiation, ch. 4.
}

${ }^{14}$ Kapstein, for example, contrasts 'specific' with 'diffused' reciprocity in his discussion of international fair trade: see Ethan Kapstein, Economic Justice in an Unfair World: toward a level playing field (Princeton, NJ: Princeton University Press, 2006), ch. 2. The distinction was originally introduced in Robert Keohane, 'Reciprocity in International Relations' in his International Institutions and State Power: Essays in International Relations (Boulder, CO: Westview Press, 1989), p. 134. It is not altogether clear what Kapstein means by 'diffused reciprocity', but it seems to indicate a looser form of reciprocity that is consistent with offering more favourable trade rules to developing countries.

${ }^{15}$ For an excellent assessment of the arguments for and against special and differentiated treatment, see Christensen, 'Fair Trade, Formal Equality, and Preferential Treatment', pp. 507-14. 
to protect their infant industries against competition from big corporations in the developed societies. ${ }^{16}$

The first three conceptions of fair trade all locate fairness in the rules applied by states to govern trading relations. The assumption is that so long as the ground rules are fair the results of the practice, in the sense of the distribution of gains from trade, will also be fair. The remaining conceptions I shall consider challenge this assumption. They argue that we must look behind the rules to see what is actually going on when goods and services are exchanged, and/or at the resulting division of benefits. So next consider:

4. Trade is fair to the extent that it corresponds to the exchanges that would occur in a fully competitive market. The underlying idea here is that existing patterns of trade reflect, to a greater or lesser extent, market distortions such as monopoly power. The claim is that fair trade in coffee, for example, means trade at the prices and on the terms that would obtain if there were many buyers of coffee beans as well as many sellers, and open competition on either side. If these conditions cannot be met, then a fair trade policy would be one that tries to correct for the effects of unequal market power and other competitive failures, for example by controlling prices.

This conception of fair trade has the advantage that it attends to power differentials between trading partners and looks to what would happen in the absence of such differentials; it also picks up a common way of thinking about fair exchange, which is to use exchange at competitive market prices as a benchmark and regard exchange on other terms as unfair unless it is consensually agreed between the parties. On the other hand, since it is a counterfactual conception, it is liable to be indeterminate. This is not just because of the empirical difficulty in establishing what the terms of exchange for some commodity would be if we removed certain specified failures of market competition, but because it is not clear how far we should take the counterfactualising.

\footnotetext{
${ }^{16}$ I take no stand here on the question whether infant industry protection, or other forms of 'special and differential treatment', are actually in the overall best interests of developing countries; for a balanced discussion see Brown and Stern, 'Concepts of Fairness', pp. 297-8, 303-5. My aim is simply to clarify the grounds on which fairness in trade might seem to call for such treatment.
} 
There is no obvious way to decide what should be counted as among the conditions for a fully competitive market, and what should be treated as external factors that participants bring to the market itself. Suppose producers in developed countries have easy access to capital loans whereas their counterparts in developing countries do not. Should these factors too be treated as 'market distortions' which work to the advantage of one side when trade occurs? Or should they rather be seen as background conditions that are irrelevant if we are trying to identify what counts as fair trade, rather than aiming for some more general goal such as greater global equality? Because of this indeterminacy, it appears that this conception works better as a way of identifying what is clearly 'unfair trade' than as a way of specifying what fair trade itself might mean.

I turn next to conceptions that focus on the impact of trade on the life-chances of the vulnerable parties - conceptions, in other words, which claim that for trade to be fair, it must not expose one side to certain forms of disadvantage. This way of thinking must be in the minds of those who present fair trade as the alternative to third world sweatshops, child labour etc. Such practices breach the minimal standards of human well-being which fair trade, by implication, must deliver.

5. Fair trade must be trade that does not involve violations of the human rights of either trading partner. Mathias Risse has recently spelt out such a conception, using the language of oppression. ${ }^{17}$ He describes a situation in which state B trades with state A, some of whose population are oppressed, and where the gains from trade occur at the expense of this part of the population. According to Risse 'these conditions render trade partly constitutive of the oppression and thus are sufficient to give the oppressed a complaint in fairness against a trading partner. Such trade is like ongoing trade with stolen goods' ${ }^{18}$ He argues that it is no defence against the charge of unfairness that the oppression would continue even if the trade did not occur. This shows that the conception of fairness at work here has a deontological character. Benefiting from participation in a trading practice that exposes trading partners to violations of basic

\footnotetext{
${ }^{17}$ Matthias Risse, 'Fairness in trade I: obligations from trading and the Pauper-Labor Argument', Politics, Philosophy and Economics 6 (2007), pp. 355-77. Risse's overall understanding of fair trade is broader than this, so here I am focussing on one prominent strand in his discussion.

${ }^{18}$ Risse, 'Fairness in trade’, p. 362.
} 
rights - being forced to work under unsafe conditions, for example - means being complicit in the oppression even if the overall impact of the trade is positive for both parties. Risse concedes that there may then be a dilemma as to whether to continue trading unfairly, if good consequences may come of this (longer-term economic growth, for example). ${ }^{19}$

It does not seem, however, that non-oppression as understood here is a sufficient condition for fair trade. First, Risse's criterion treats trade as unfair only when it contributes to violations of the negative rights of one party. That is, it does not include cases where trade simply leaves one party very badly off, even though there is no oppression involved, cases which might seem problematic if one thinks that interacting with people via a practice of trade may create positive duties of aid. ${ }^{20}$ Second, it obviously does not apply to trade between partners all of whose human rights are secure, whereas we might think that issues of fairness can arise even in cases where there is no threat of coercion or oppression. ${ }^{21}$ Third, there is a sense in which Risse's approach does not focus specifically on fairness in trade. His criterion applies whenever there is interaction between people from which one party benefits but oppression on the other side that helps create the benefit. The problem with trade, in the cases that Risse has in mind, is not internal to the practice of trade itself; it is rather that the possibility of selling their goods abroad creates the conditions under which employers can force workers to work in sweatshops etc. Their trading partners thereby become complicit in the oppression, but only in the same way that tourists, for example, might become complicit in supporting oppressive regimes by giving the agents of such

${ }^{19}$ Risse, 'Fairness in trade’, p. 363.

${ }^{20}$ This seems to me plausible, though not self-evident. For a more sceptical view, see Andrew Walton, 'Do Moral Duties Arise from Global Trade?', Moral Philosophy and Politics 1 (2014), pp. 249-68.

${ }^{21}$ See the critical appraisal of Risse in Helena de Bres, 'Risse on Justice in Trade', Ethics and International Affairs 28 (2014), pp. 489-99. As de Bres remarks, 'there is a kind of advantage-taking, rampant in international trade, that does not directly concern unjust terms of employment occurring in foreign lands. Instead, it involves rich countries themselves routinely taking advantage of the weaker position of poorer countries in trade policy and multilateral trade negotiations' (p. 494). 
regimes access to hard currency. One might then say that Risse's critique does not concern fairness in trade as such, but what we might call 'the ethics of trade' - i.e. the conditions under which it becomes no longer ethical to be involved in trade relations with particular states, or individuals within those states. ${ }^{22}$

6. In response to the first point above, one might strengthen the human rights condition, and define fair trade as trade that respects the human rights of both parties, where human rights are taken to include positive rights to subsistence and more generally to a minimally decent standard of living. This corresponds to one of the leading principles espoused by Fair Trade associations, namely that primary producers should receive a 'living wage', understood as a wage sufficient to support them and their families above some (unspecified) poverty threshold. How could we show that trade is only fair if it provides this? Even if there is a shared duty on the part of the citizens in rich societies to protect the human rights of outsiders, it is unclear that this translates into a duty to trade in such a way that the human rights of trading partners are protected. Why should the general duty be linked to one particular way of discharging it? This worry is expressed by Kurjanska and Risse: 'As far as we can see, trading relations do not entail special obligations. Merely by trading with A we do not acquire duties we do not have toward B. While it would be desirable if everybody had certain wages, trade relations do not trigger associative obligations to see to this. ${ }^{23}$ A prima facie objection to principle 6, therefore, is that while we may have positive obligations to protect human rights, we need not act on these obligations when we trade. We could discharge them in other ways - through supplying development aid, for example.

\footnotetext{
${ }^{22}$ In case the distinction I am drawing here is unclear, consider the case of selling arms to authoritarian regimes that may at some later stage use these weapons to oppress their subjects. Assuming that a fair price has been agreed for the weapons and other such conditions are met, what is wrong here is not that the trade itself is unfair, but that it is unethical in view of its likely consequences. The distinction is between exchanges that directly contribute to harming or wronging one of the parties and exchanges that may lead, predictably but indirectly, to later wrongs.

${ }^{23}$ Malgorzata Kurjanska and Matthias Risse, 'Fairness in Trade II: Export Subsidies and the Fair Trade movement', Politics, Philosophy and Economics 7 (2008), p. 44. See also Ostmann, 'Moral Constraints on Prices in International Commercial Transactions', to whom 'it seems implausible that external distributive demands should act as a source of moral constraints on the choice of prices in international commercial transactions'.
} 
Kurjanska and Risse's argument looks strongest, however, when one thinks about a particular instance of trade - a single commodity exchange, for example. It looks less convincing if one regards trade as a social practice structured by rules that can be changed by collective decision. ${ }^{24}$ For it may then seem that for the practice to be fair, we should consider its distributive consequences, and in particular the question whether everyone who engages in it will receive sufficient resources to fulfil their human rights, assuming that this is feasible. But the underlying problem seems to be that definition 6 is burdening trade with a general responsibility to meet human rights that it may take a battery of policy measures to discharge completely. ${ }^{25}$ As I indicated earlier, trade by definition is exchange for mutual advantage. Both partners should expect to benefit from trade, but how well off they are after trade has occurred must depend on their respective starting points. ${ }^{26}$ There cannot be a guarantee that they will be above some threshold defined apart from the trade itself. So the definition demands too much in one respect; but for reasons already alluded too, it may demand too little in other respects, because it seems, for example, that a primary producer might earn enough through trade to provide himself with a minimally decent standard of living, but still be

${ }^{24}$ This contrast is emphasized in Aaron James, 'Distributive Justice without Sovereign Rule: The Case of Trade', Social Theory and Practice 31 (2005), pp. 1-27. James argues that specific market exchanges may only be subject to fairly minimal moral requirements such as the absence of fraud or coercion, whereas social practices subject to 'collective governance' by the participants can be assessed according to more demanding requirements of 'due care' and 'distributive justice'. He argues further that international trade meets the conditions for being such a practice. For a longer version of the argument, see James, Fairness in Practice. See also Matthias Risse, On Global Justice (Princeton, NJ: Princeton University Press, 2012), p. 272 which proposes principles of distributive justice for international trade as 'a structured and repeated exchange involving markets and bodies of law'.

${ }^{25}$ One practical manifestation of this problem is the difficulties that have been encountered in trying to build human rights concerns into the agenda of the bodies that govern world trade, most recently the WTO. For an analysis and assessment, see David Kinley, Civilising Globalisation: Human Rights and the Global Economy (Cambridge: Cambridge University Press, 2009), ch. 2.

${ }^{26}$ C.f. James: 'trade can be fair to everyone it affects, according to its purpose, without amounting to a scheme for redistributing goods that exist or would equally have existed in the absence of trade.' ('Distributive Justice without Sovereign Rule', p. 14). 
treated unfairly by receiving too small a share of the value of what he has produced. This suggests that to understand fair trade we may need to focus more closely on relative shares - how much each party benefits from trade - rather than just on whether absolute shares cross a threshold such as the human rights standard.

7. We might then consider the following, quite radical, definition of fair trade: trade is fair when each party receives a return that is proportionate to the value of the items they have produced to trade. The gains of trade, in other words, must be distributed between the partners in such a way that each is adequately rewarded for their contribution. We can hear such an idea being expressed in frequently voiced complaints that when goods such as coffee are traded, the primary producers only receive a tiny fraction of the final selling price. Although it is not disputed that processing companies and others add value to the coffee along the way, the claim is that the distribution of the final value the price for which coffee is sold in Western supermarkets, say - is unfair.

Since, by assumption, the prices actually being offered to producers do not reflect the value of what they have produced, we would need to find some independent measure of value to make definition 7 workable. One possibility would be to identify value as the price that a product would command in a competitive market. This however would take us back to definition 4 and its attendant problems. The alternative is to take inspiration from the Marxist tradition and say that a producer's contribution is measured by the labour that she necessarily performs in making her product. We find this idea used in debates about fair trade when critics point out that it may take a farm worker in a developing country many months to earn enough money to buy a product that an industrial worker in the North makes in a few hours. Implicitly, fair trade would mean that products should exchange according to the hours of labour that each embodies. A more sophisticated view, adopted for example by Emmanuel in his classic work on trade as unequal exchange ${ }^{27}$, allows that labour may have different degrees of skill and intensity, so the value of any product has to be estimated taking these factors into account as well. The claim, then, is that even if we allow that the labour performed by a worker in a developed country is, say, three times as intense as that performed by a

\footnotetext{
${ }^{27}$ Arghiri Emmanuel, Unequal Exchange: A Study of the Imperialism of Trade (London: New Left Books, 1972).
} 
peasant farmer in a poor country, their products actually exchange at a ratio far higher than three to one (in Emmanuel's case this is shown by the relative wages that each is able to command). The trade is unfair because equivalents are not being exchanged.

Clearly, everything depends here on being able to find a measure of labour value that is independent of the exchange value of the commodity produced as shown by the price it can command when it is traded. Once it is accepted that labour is multidimensional - that it can be more or less skilled, can be deployed more or less effectively, etc. there seems to be no obvious way of combining these dimensions to generate a single index of labour value. One can solve the problem by using the market price of the product to measure the productivity of the labour that has created it, but this immediately undercuts the idea of unequal exchange, since it now follows necessarily that when two products are exchanged under normal market conditions, the value embodied in each of them must be the same. (Thus Emmanuel's particular concept of unequal exchange has been criticized on the ground that the wage inequalities he points to are in fact closely correlated with differences in productivity - the latter presumably being measured in terms of the prices at which products exchange on the international market. ${ }^{28}$ )

Faced with this dilemma someone might retreat to the simple view and say that trade is only fair when products exchange at ratios determined by the time that it takes to make them. But this would run counter to the idea of trade itself, which as I noted earlier must be based on mutual advantage. Even though one might in general expect producers to gain by exchanging their products with others, there is no reason to think that B will be willing to take the product it takes A 10 hours to make in exchange for the product that he has laboured on for the same amount of time; he may well agree to exchange, but not at that price. ${ }^{29}$ Trade constrained by the requirement of equal

\footnotetext{
${ }^{28}$ See Michael Barratt Brown, Fair Trade: Reform and Realities in the International Trading System (London: Zed Books, 1993), p. 43.

${ }^{29}$ As evidence for this proposition, consider the short-lived Labour Exchanges that appeared in Britain in the 1830s, in which workers would deposit their products in return for 'Labour Notes' (denominated in hours of labour), which could then be used to purchase other products. Predictably, the Exchanges were left with goods that no-
} 
exchange so understood would probably only amount to a small fraction of the trade that would occur if parties are permitted to exchange at market-clearing prices.

8. There is, however, another way to measure the relative gains that trading partners receive from their exchange. Instead of trying to measure what each contributes, by some standard, we could look instead at the benefit that each receives. Since trade is mutually beneficial, each side must receive more (even if only marginally more) than the lowest price at which they would be willing to exchange their goods. The distance between these prices is the surplus that has to be distributed somehow between the parties. To see the basic idea, consider first an exchange between individuals. Suppose that I have some tomatoes to trade and my neighbour has apples. I am willing to exchange a kilo of tomatoes for two kilos of apples, but not for less. My neighbour will be happy so long as he gets at least a kilo of tomatoes for each three kilos of apples that he trades. ${ }^{30}$ Clearly we can exchange at any apple/tomato ratio between 2:1 and 3:1: the surplus to be distributed is the equivalent of 1 kilo of apples. If we exchange at 3:1 I get the whole of it; at 2:1 my neighbour gets the whole of it; at any rate in between we share it.

In these circumstances, an obvious principle of fairness to apply is equal division of the surplus. ${ }^{31}$ Equal division is the principle we are likely to use when two or more people enjoy a windfall benefit and no-one has any particular claim to more of the benefit than anyone else. ${ }^{32}$ Here we would treat the opportunity provided by trade as the equivalent

one was willing to buy for the stated prices. See G.D.H. Cole, The Life of Robert Owen, $2^{\text {nd }}$ edition (London: Macmillan, 1930), ch. 15.

${ }^{30} \mathrm{I}$ am assuming that these ratios remain constant over the quantities of tomatoes and apples we are interested in exchanging. This would obviously not make sense as a general postulate.

31 This principle is also defended in James, Fairness in Practice, ch. 7, though in a different form from the version considered here. James proposes to aggregate the gains from international trade and then to distribute them equally, first between and then within trading societies. In contrast to this macro-level version of the principle, I examine the equal division principle applied directly to the surplus generated by a specific instance of trade between two parties. 
of a windfall: it is fortunate for my neighbour and I that we can exchange our products and both be better off as a result, so what fairness requires is that we should trade in such a way that the benefit is equally distributed. But we face a problem in deciding how this benefit is measured. There are two possible currencies - apples and tomatoes - and my neighbour and I value them differently relative to one another. So an equal gain measured in terms of apples is not the same as an equal gain measured in terms of tomatoes. ${ }^{33}$

It might appear as though this problem arises because in the simple model I have used, one good is being exchanged directly for another. If we think about real world trade, however, goods are sold for money: a coffee grower sells his beans to the processing company at so much per kilo. Assuming that there is a gap between the lowest price that the grower will take and the highest price that the company will pay, then an equal division of the surplus would require selling the beans at the mean of those two figures. However this overlooks the fact that a sum of money represents a bundle of commodities that can be bought with that sum, so we still have two different currencies in which the gains can be measured - coffee beans on the one hand, and the commodity bundle on the other. The two sides value these currencies differently relative to one another. So, just as in the tomatoes/apples case, there will still be two possible ways of specifying an equal division of the gains from trade.

Nevertheless, even if there is no unique way of specifying what an equal division of the surplus means, we might still say that fair exchange requires that goods be exchanged in a proportion that lies somewhere between the two possible 'equal' divisions we have

\footnotetext{
${ }^{32}$ For the salience of equality as the rule to be followed when assets have to be divided by agreement, see H. Peyton Young, Equity: in theory and practice (Princeton, NJ: Princeton University Press, 1994), esp. ch. 7.
}

${ }^{33}$ Suppose we exchange at the rate of 2.5 kilos of apples to 1 kilo of tomatoes. At that ratio each us gains a surplus of 0.5 kilos of apples over his baseline. But now repeat the calculation using tomatoes as the currency in which the surplus is measured. At 2.5:1 my gain will be 0.25 kilos of tomatoes (I would have been willing to give 1.25 kilos of tomatoes for those apples); my neighbour's gain is only $0.16666 \ldots$.. (it would require 5/6 kilo of tomatoes to make him part willingly with 2.5 kilos of apples). To achieve an equal division of the surplus measured in tomatoes, we need to exchange in the ratio 2.4:1. 
identified - i.e. between 2.4:1 and 2.5:1 apples to tomatoes, in the simple example used above. This obviously represents a considerable narrowing of the range of possible trades, which runs from 2:1 to 3:1. So the idea of fair trade is still doing some work here. Many exchanges that might occur voluntarily will not count as fair, even if there is no trade that uniquely does. So now let us ask what can be said for and against this way of understanding fair trade.

In addition to the currency problem, the equal benefit principle requires us to know what the reserve prices of the two sides actually are, because this provides the baseline from which we can measure an equal division of the surplus. So each party has an incentive to misrepresent that reserve price. Suppose my neighbour falsely claims that he is only willing to give a maximum of 2.5 kilos of apples for each kilo of tomatoes. If we were to calculate on that basis, the fair exchange ratio would lie in the region 2.222...:1 to 2.25:1, lower than the region identified in the original example. However although that would clearly be a serious practical problem if we were attempting to devise a fair trade policy, it does not seem to undermine the concept of fair trade itself. What it does show is that there is no reason to expect bargaining between the parties to deliver the fair result if they do not know one another's true reserve prices (in fact bargaining will not necessarily do that even if the parties are fully informed about this $\left.^{34}\right)$.

A further problem of application which I will note here but not try to resolve is that trade is a collective activity insofar as goods and services are typically created by many producers and sold to many consumers, so on each side there will be a range of reserve prices, not just a single one; yet when a commodity is traded across national borders, it is normally at a uniform price (there is at any moment a 'world market price' for oil or coffee beans of a particular grade). So we cannot tell whether this uniform price stands midway between reserve prices on either side without amalgamating these individual prices into a single price in some non-arbitrary way - a formidable challenge.

\footnotetext{
34 This is because of different attitudes to risk, given that if the parties fail to agree no exchange takes place and both lose: see Young, Equity, ch. 7.
} 
Another objection might be that a definition of 'equal benefit' that measures it in terms of the quantities of commodities that are being exchanged does not take account of possible differences in the welfare or utility gains of the two parties. However it seems to me that fairness is better understood, in general, in terms of shares of some external resource, or bundle of resources, rather than in terms of subjective states such as welfare. The fact that one party comes away from an exchange happier than the other - in the sense that the first party has derived more utility from it than the second - does not show that the exchange was unfair unless it is treated as evidence that the terms of the exchange were one-sided, which would mean, following the proposal above, that one party had captured the lion's share of the surplus, measured objectively. Indeed if we are thinking about world trade between rich and poor countries, it may well be the case that the welfare gains from trade are relatively greater for those in poor countries; but it would be somewhat paradoxical if for that reason we were to label the trade unfair.

A more serious problem arises if we consider cases in which one side is desperate to exchange what they have for necessities, so they are willing to accept a very low price for their commodities. We may think of the coffee grower who has nothing to live on apart from the beans he has grown, which if not sold now will deteriorate and become worthless. He would be willing to sell for a very low price, and this will then have the effect of reducing the fair price, understood as the price that equalizes the gains of buyer and seller (it won't of course lower the fair price all the way down). The implication is that an acceptable conception of fair trade has to consider the background circumstances in which trade occurs as well as the mechanics of the exchange itself.

We need to be clear about the nature of this objection to my proposal 8. It is not the same as the charge that trade may be both voluntary and exploitative. In the circumstances just described, coffee buyers may well take advantage of the grower's desperation to buy his beans at virtually his reserve price, thereby making huge gains themselves. This would be exploitation brought about by power inequalities between the two parties (the buyer can force the grower to sell at a low price). The proposal 8 definition of fair trade rules out such exploitative exchanges by requiring that the gains from trade be equally distributed between the two sides. So the objection is not that it allows exploitative trades to be defined as fair, but that by calculating gains on the basis of reserve prices, it allows the fair rate of exchange for some commodity to be affected 
by the neediness or desperation of one party. Put simply, the claim is that the fair price for coffee beans should not sink merely because coffee growers become more desperate and are therefore willing to sell at a lower rate.

This intuition will probably be shared by many people, so it is worth exploring what grounds it. It may stem from a conception of fair trade along the lines of proposal 4 above; that is, the underlying thought may be that the fair price for coffee is the price that it would command in a fully competitive market, and this is independent of price fluctuations caused by the fact that there are suddenly many producers who need to sell their beans. This conception, it should be noted, does not imply that the fair price should provide coffee growers with any particular level of income such as a 'living wage'. In contrast, the underlying thought may be that there is some absolute threshold price for which coffee beans should sell - a price that would give the growers a decent subsistence - and this is unaffected by the price that growers are actually willing to take at any moment. This would reflect an understanding of fair trade such as that encapsulated in proposal 6 discussed above.

Although I have criticised both proposal 4 and proposal 6 earlier on in the paper, let us grant that the intuition reported above is sufficiently powerful to defeat proposal 8 as a complete account of fair trade. If so, it appears that none of the eight proposals I have considered fully captures that concept; at most each identifies something that contributes to making trade fair. Let me briefly review these proposals again. They fall into three broad categories. First, we have procedural fairness accounts of fair trade. These highlight the rules under which trade takes place, and make different recommendations as to which rules should be adopted. There is no reference to the outcomes of trade, and it is assumed that trade itself will be conducted on the basis of self-interest (either individual or collective) within these rules. Although efficiency considerations weigh heavily in these conceptions, they also appeal to an idea of equality of opportunity for nations and/or producers. Such accounts can thereby be presented as favourable to the interests of people who work in developing countries. ${ }^{35}$

35 This is, for example, the general theme of Joseph Stiglitz and Andrew Charlton, Fair Trade for All: How Trade can promote Development (Oxford: Oxford University Press, 2005). 
Next, focusing on the position of such groups, we have what may be labelled producers' entitlements conceptions of fair trade. These claim that trade must be structured in such a way that everyone who contributes to the practice is safeguarded against certain harms, whether exploitation or poverty. The institutional rules of trade may be important, but they are not by themselves sufficiently protective of certain groups. Producers' entitlements conceptions impose duties on everyone involved in trade to concern themselves with the welfare of potentially vulnerable trading partners, or at the very least not to become complicit in harming them. In this respect such conceptions of fair trade are broader than procedural conceptions, but in another respect they are narrower, because they have no direct bearing on trade between prosperous states or individuals, where the relevant entitlements are already secure.

Lastly we have fair exchange accounts of fair trade. These look directly at what goes on inside the practice of trading and claim that exchanges must be conducted on terms that produce a particular division of resources or benefits between the trading partners. On the assumption that trade produces gains that can be divided in different ways between the parties to it, such conceptions propose principles to govern the division. As in the case of procedural fairness conceptions, fair exchange accounts make the reasonable assumption, given the current state of the global economy, that fair trade so defined would benefit producers in poor countries; but there is no guarantee that fair trade by itself will raise these producers above any particular poverty line. ${ }^{36}$

Fair exchange accounts might seem less relevant than the other two conceptions to the design of international trade policy. After all no authority can inspect each particular trade practice to ensure that the gains are being fairly distributed. So these conceptions cannot be implemented directly, except by the trading partners themselves. Yet they may still serve as guiding principles when rules of trade are being debated. There are trading conditions that clearly militate against fair exchange, such as the emergence of monopoly or monopsony, and the rules can be designed to prevent such conditions

\footnotetext{
${ }^{36}$ See further here Aaron James, 'Equality in a Realistic Utopia', Social Theory and Practice 32 (2006), pp. 718-19.
} 
emerging, or to provide compensation to parties who can prove that they have been dealt with unfairly.

Perhaps, then, we should see these competing conceptions of fair trade as complementary to one another, in the sense that different aspects of fairness in trade are likely to be highlighted in different contexts: GATT officials and Fair Trade campaigners have different considerations in mind when they appeal to the idea. In some cases, moreover, the different conceptions will pull in the same direction, practically speaking. But not always: consider for example the 'banana wars' that erupted between the US and the EU in the 1990s. ${ }^{37}$ The issue here was the favourable conditions of trade in bananas that some EU countries had extended to their former colonies in the Caribbean and West Africa. Bananas from these countries were admitted tariff free, whereas a tariff was imposed on bananas (over and above a certain quota) produced in Latin American countries such as Ecuador. The US (whose multinationals dominated the Latin American banana industry) challenged this on grounds of procedural fairness: the more efficient Latin American banana growers should not have to compete on unequal terms against growers in the Caribbean and West Africa. The counterargument appealed to the vulnerability of the small farmers in the latter regions. Britain and France, for example, had traditionally imported almost all their bananas from their former colonies, and had provided assurances that this would continue. Local economies were heavily dependent on the export of bananas (they constituted 70\% of Dominica's export earnings, for example), so without the protected banana trade these societies were threatened with economic collapse. Producers' entitlements here collided with procedural fairness - certainly with the understandings of procedural fairness contained in proposals 1 and 2 above, and arguably also with proposal 3 , since all of the banana-growing countries could claim developing country status. What stood on the other side was really a claim of necessity: the big Latin American producers could survive even if the special concessions give to the ex-colonies were allowed to continue (the volume of trade involved was comparatively very small) whereas in the reverse case the small growers could not.

\footnotetext{
${ }^{37}$ I rely here on Banana Wars: Challenges to the European Union's Banana Regime (Harvard University: Kennedy School of Government Case Program C14-99-1534.0).
} 
In concrete cases, therefore, different aspects of the idea of fair trade may pull in different directions. This is not a reason for abandoning the idea, but for recognizing its complexity. Let me by way of conclusion return to the place it might occupy in our thinking about justice beyond (national) borders. Much will depend on whether we stick to a simple conception of global justice that concerns the distribution of resources among individual persons, or whether we also allow that it has an interactional component - i.e. that it matters on what terms people interact globally, not just what the final outcome of the process is. And we must also decide, as I suggested earlier, whether this interactional component applies not only to individuals but also to political communities. This second possibility is by no means uncontroversial. It relies on the idea that in a world of nation-states, where people identify strongly with these political units, they can suffer from injustice through their membership of these units, as well as in their individual capacity. ${ }^{38}$ But it seems to be presupposed by some of the ideas of fair trade we have considered. If one insists that two states should conduct their trade on terms of reciprocity, this invokes fairness between these two collective units, as well as fairness between individuals within the units who may be involved in trade.

In my general treatment of global justice, I suggested that fair trade should be identified as one of the main elements included in the more general idea of 'fair terms of cooperation' between states. $^{39}$ My claim was that economic inequalities between societies could be acceptable provided that the international order provided poorer societies with reasonable opportunities to develop. Closer inspection of the concept of fair trade suggests that this is only part of the story, albeit an important part. Fair trade is indeed a matter of political communities treating one another fairly when they establish rules governing tariffs, subsidies, quotas and so forth. But it also has to do

\footnotetext{
${ }^{38}$ The same issue arises in other contexts, for example in discussions about how to distribute the costs of combating global warming, where it appears that this is in the first place a question about how to share costs between states, and only secondarily a question about how to allocate costs to individuals within those states. Or for a more frivolous example, imagine that the International Olympic Committee decided for some arbitrary reason to exclude certain countries from participation in the Olympic Games. This would be unfair to individual athletes from those countries, obviously. But it would also be unfair to those countries themselves; their citizens would feel wronged whether or not they had any personal involvement in sport.

39 (reference removed)
} 
with how individuals are treated, as our investigation of producers' entitlements conceptions showed. In other words, fair trade is also relevant to the part of global justice that concerns the protection of human rights. It cannot be the only instrument that serves to protect these rights, in part, as we saw, because of limitations built into the very idea of trade itself. Not all economic transactions that might serve to protect the human rights of poor people will count as trade. Nevertheless, trade on the right terms does seem to offer a dignified and secure way for many poor people to fulfil their rights to subsistence (and thereby other connected rights such as those to health care and education).

So this exploration of the meaning and normative significance of fair trade leaves us with a question: what weight should we give to the different elements contained within that idea when they conflict? How much does it matter that political communities should interact economically under rules that are seen to be fair, and how much that the impact of trade on the lives of individual people should meet substantive standards of (comparative or non-comparative) justice? There is no easy way to answer this question. 